\title{
RECUPERAR EL LEGADO HISTÓRICO Y ETNOGRÁFICO DE HENRI PITTIER
}

\section{RECOVER THE HISTORICAL AND ETHNOGRAPHIC LEGACY OF HENRI PITTIER}

\author{
Carlos Cruz Meléndez*
}

\begin{abstract}
Resumen: Henri Pittier es un científico de origen suizo, quien realiza una extensa como dilatada investigación en la Costa Rica de finales del siglo XIX e inicios del siglo XX en campos como la botánica y la geografía. Pero también incursiona en áreas de la lingüística, la etnografía y la historia. En este ensayo se busca mostrar la importancia que, en particular para las ciencias sociales, tiene la recuperación y estudio de este legado. Para este propósito y a manera de ejemplos, se comenta la actualidad y pertinencia de tres ensayos o informes del investigador donde se abordan temas como la longevidad de los habitantes de la región nicoyana, las costumbres de los pueblos indígenas y su relación con el Estado, o el proceso de expansión de la sociedad nacional costarricense hacia la actualmente denominada "Zona Sur".
\end{abstract}

Palabras clave: Henri Pittier; Costa Rica; etnografía; lingüística; historia.

\begin{abstract}
Henri Pittier is a scientist of Swiss origin, who performs an extensive and dilated research in Costa Rica in the late nineteenth and early twentieth century on fields like botany and geography. But it also ventures into areas of linguistics, ethnography and history. This essay seeks to show the importance that, in particular, for the social sciences, the recovery and study of this legacy has. For this purpose and as examples, I will comment on the relevance and pertinence of three essay or reports of the researcher where issues such as the longevity of
\end{abstract}

Fecha de recepción: 17/09/2018-Fecha de aceptación: 01/10/2018

* Costarricense. Antropólogo y sociólogo. Académico y coordinador del Centro de Información Documental en Ciencias Sociales (CIDCSO) de la Universidad Nacional (UNA), Costa Rica. Correo electrónico: carlos.cruz.melendez@una.cr 
the inhabitants of the region of Nicoya are addressed, the customs of indigenous peoples and their relationship with the State, or the process of the expansion of the Costa Rican national society towards the currently called "Zona Sur".

Keywords: Henri Pittier; Costa Rica; Ethnography; Linguistics, History.

\title{
Introducción
}

\begin{abstract}
"Volviendo a los indios, Gómez asegura que en su tiempo éstos recibían esmerada protección de parte de leyes y soberanos españoles. Se mantenían apartados como casta distinta y los regían especiales ordenanzas: por ejemplo, estaban exentos de las contribuciones comunes y sólo se les exigía el pago de un real por cabeza y por año. Tributo que enviaba directamente al Rey.
\end{abstract}

"En todo tenían más mérito que los negros, y el que sacaba sangre a alguno de ellos, lo hostilizaban y perseguían al extremo de que tenía que alejarse del lugar". Como es sabido, los naturales de Nicoya no formaban ya en esa época una raza homogénea. Haciendo abstracción de los probables pobladores primitivos de la península, acerca de quienes no tenemos datos fidedignos, aquélla era ocupada por los indios Chorotegas o Cholutecas, cuyo origen era Cholula, en la parte central de Méjico. Según nos ha sido trasmitido por los cronistas de la conquista, estos indios, cansados de la opresión en que los mantenían los Olmecas después de haberlos vencido en áspera lucha, abandonaron aquella patria y se dirigieron hacia el Sur, siguiendo la costa del Pacífico".

Henri Pittier, "Impresiones y recuerdos: José Silverio Gómez 1801-1904".1

Los denominados relatos, crónicas, informes, diarios, etc., de viajeros, se han constituido en una importante fuente de información en el estudio histórico de diferentes sociedades y, ciertamente, Costa Rica no es la excepción. Así, la recuperación y aprovechamiento de estos materiales en la investigación sobre múltiples como diversas realidades sociales que han ocupado a lo largo del tiempo el hoy territorio costarricense ha sido una tarea constante de los científicos sociales. Solo a manera de ilustración, se puede pensar en trabajos de historiadores como Carlos Meléndez Chaverri² o de Ricardo Fernández Guardia ${ }^{3}$. Siendo el propósito de la presente reflexión resaltar, desde esta perspectiva, la existencia de la extraordinaria obra sobre Costa Rica del científico de origen suizo Dr. Henri Pittier Dormond, legado de más de 17 años de trabajo de campo

1 Henri Pittier, "Impresiones y recuerdos: José Silverio Gómez (1801-1904)", en: Adina Conejo Guevara, Henri Pittier: Presentado por Adina Conejo (San José, Costa Rica: Ministerio de Cultura, Juventud y Deportes, Serie “¿Quién fue y qué hizo?”, № 20, 1975), 163, 136-137.

2 Carlos Meléndez Chaverri, Viajeros por Guanacaste (San José, Costa Rica: Ministerio de Cultura, Juventud y Deportes, , Serie "Nos Ven", No 12, 1974), 557.

3 Ricardo Fernández Guardia (introducción, notas y traducción), Costa Rica en el siglo XIX: Antología de viajeros (San José, Costa Rica: EUNED, 2002), 516. 
por todo el territorio nacional, que todavía espera ser conocida en su totalidad y, sin duda, aguarda la profundización en su aprovechamiento. Se está al frente de un caso especial, ya que no solo se tiene la circunstancia de una dilatada presencia en Costa Rica, con múltiples viajes de trabajo de campo al "interior" del país, sino, además, el hecho de ser el producto de la labor acuciosa, sistemática, como detallada de un científico de formación. Un europeo con estudios académicos del más alto nivel en ciencias e ingeniería civil, pero quien además incursionaría con toda propiedad en campos de la historia, la etnografía y la lingüística.

Arriba, a manera de epígrafe, se reproduce parte de un trabajo publicado a principios del siglo XX que hiciera Pittier sobre la base de una entrevista a un nicoyano de más de cien años, quien se convierte en un informante privilegiado, en un testigo de todo el siglo XIX, para que el investigador se adentre en la historia de la región de Nicoya, Guanacaste. Por medio de su informante, José Silverio Gómez, el científico busca conocer los más diversos aspectos de cómo ha sido la historia de estas gentes, en particular pueblos indígenas, su organización social y costumbres, así como la interacción entre ellos y con la administración colonial primero y luego estatal costarricense que se ha venido dando en la Península de Nicoya. Pero a los ojos del investigador, simultáneamente, el mismo informante se torna en objeto de interés científico, ya que el estudioso se percata que la longevidad de José Silverio no es un hecho excepcional sino, por el contrario, lo raro, lo que llama la atención es lo frecuente en la región nicoyana de personas de muy larga vida. Y es así, como se profundizará más abajo, que Pittier se adelanta en un siglo al quehacer científico internacional al indicar la existencia de un fenómeno demográfico circunscrito geográficamente y caracterizado por una prolongada expectativa de vida de sus habitantes que para inicios del siglo XXI se conocerá como una "zona azul". Un ejemplo de la pertinencia y actualidad de la labor de investigación histórica y etnográfica que desarrollara Henri Pittier sobre la historia y las gentes de lo que hoy es Costa Rica y que se debería recuperar en su totalidad.

Este hombre de ciencias, quien nació en Suiza en 1857 y murió en Venezuela en 1950, habría de pasar, pues, casi dieciocho años en suelo costarricense -donde llegó a finales de 1887- en los cuales no solo promovería la creación y desarrollo de una institucionalidad estatal necesaria para el conocimiento objetivo y veraz de la realidad del joven país -como es el caso, por ejemplo, del Instituto Meteorológico o del Instituto Físico-Geográfico-, sino que asimismo emprendería personalmente innumerables empresas dirigidas a investigar y documentar de manera integral y abarcadora todo lo relacionado con la biodiversidad, el clima, el territorio, pero también, las diferentes gentes que habitaban el país. Así y más allá de destacar la singular figura del científico-explorador, este breve ensayo se centra en resaltar la actualidad de esa fuera de serie herencia de Pittier en función del estudio contemporáneo de diversos ámbitos de la realidad 
sociohistórica costarricense. Si bien Pittier es conocido en Costa Rica -aunque no recuperado todavía en toda la amplitud y profundidad de su gigantesca obraen áreas de las denominadas "ciencias naturales", tales como la geografía o la botánica, resulta que muchos de sus trabajos relacionados con la etnografía, la lingüística y la historia, permanecen todavía relegados en el olvido.

Como ilustración de la actualidad y pertinencia de la obra de Pittier en el ámbito de las ciencias sociales, en la presente reflexión se comentan tres de los once ejemplos de los trabajos del helvético, que recupera en su obra de 1975, sobre el aporte de este hombre de ciencias en Costa Rica, la historiadora Adina Conejo Guevara -los textos "Ojeada general sobre el Valle del Diquís o Río de Térraba", "Ceremonias fúnebres" e "Impresiones y recuerdos: José Silverio Gómez"- ${ }^{4}$ presentando algunas meditaciones sobre estos para tratar de mostrar cómo continúan aportando información relevante sobre líneas de investigación de las que se ocupa hoy la comunidad científica nacional.

\section{La invitación de Adina Conejo Guevara}

Sobre la base de su tesis de licenciatura en historia y geografía de 1972 en la Universidad de Costa Rica, Adina Conejo Guevara publica en 1975 la más acabada hasta hoy recuperación del paso de Henri Pittier por este país centroamericano. Un texto que puede ser leído como una sobria y motivadora invitación que hace de hecho la autora, desde una perspectiva costarricense, ${ }^{5}$ sobre la necesidad de recuperar todo el amplísimo legado de conocimientos producto de esos 17 años de arduo y continuo trabajo en Costa Rica del científico europeo. ${ }^{6}$ Siendo la presente reflexión una reacción a esa invitación.

4 Conejo Guevara, Henri Pittier: ..., 77-82, 114-119 y 125-141.

5 En cada país donde estuvo y para el cual trabajó -principalmente los casos de Costa Rica, los Estados Unidos y Venezuela-, el investigador suizo dejó una indeleble huella conformada siempre y sobre todo de una fructífera, dilatada como penetrante labor de investigación, mediante la cual sistematizaba y documentaba en detalle sus hallazgos sobre las nuevas realidades que enfrentaba como científico.

6 Adina Conejo organiza su texto de la siguiente forma: en el primer capítulo de esta obra, se hace un bosquejo biográfico de la notable como dilatada vida de Pittier, incluyendo sus años en Costa Rica, su aporte al desarrollo institucional estatal y al conocimiento de la realidad nacional. Un segundo capítulo, ubica el contexto del desarrollo científico europeo de la época, para destacar desde este punto de referencia la gran valía, variedad y complejidad del trabajo de "modernización" que Pittier emprende en Costa Rica. El tercero ofrece un recuento de los principales viajes de exploración-investigación, junto con once textos cortos que resumen los resultados de esa labor de indagación por medio de esos viajes de exploración que le permiten adentrarse en el territorio costarricense y en el conocimiento de sus habitantes, y en el cuarto incluye cartas, un cuadro cronológico y una bibliografía básica de la obra acerca de Costa Rica, publicada por Pittier. Hay un error en la página 153 del texto, donde se inicia el apartado que contiene una bibliografía básica de las obras publicadas sobre Costa Rica de Pittier, ya que el título de este apartado es "Biografía básica", cuando se trata, de una recuperación de textos publicados por el científico suizo. Para efectos de esta reseña y en beneficio del lector interesado, se ha tomado entonces la libertad de hablar de "Bibliografía básica". 
Se trata de mostrar la eventual importancia científica que tiene el recuperar los muy diversos como valiosos, por actuales, resultados de más de tres lustros explorando lo más recóndito del territorio nacional, sistematizando y documentando cada detalle de sus hallazgos, que ese investigador helvético dejara a las generaciones futuras sobre muy diversas facetas de la Costa Rica de finales del siglo XIX y principios del XX, sea de su geografía o sea de su biología, pero también, y foco de la presente reflexión sobre la actualidad de la obra de Pittier, acerca de sus gentes. Sobre todo, tener presente la necesidad de conocer los resultados de sus muchas empresas para investigar y documentar en todo lo que fuera posible acerca de un territorio nacional y sus habitantes todavía inmersos en el desconocimiento desde la óptica de la sociedad nacional que se construía a partir del Valle Central. Si bien se tiene que Henri Pittier es mejor conocido en Costa Rica, pero no recuperado todavía en toda la amplitud y profundidad de su gigantesca obra, en áreas de las denominadas "ciencias naturales", tales como la geografía o la botánica, se tiene que muchos de sus trabajos relacionados con la etnografía, la lingüística y la historia permanecen todavía relegados en el olvido. $\mathrm{Y}$ es, entonces, desde la perspectiva de valorar la actualidad de estos aportes de Henri Pittier al conocimiento histórico y etnográfico de las gentes que han habitado el territorio hoy costarricense, que cobra un enorme valor el recuperar el legado del científico suizo.

Adina Conejo se propone y logra acercar al lector a la sin lugar a duda sorprendente empresa científica que emprendió Pittier en Costa Rica:

\footnotetext{
"Ponemos a la disposición de los lectores el presente ensayo biográfico, sobre la vida y obra del ilustre científico Dr. Henri Pittier; lo hacemos con el profundo deseo de que se popularice el conocimiento de tan distinguida figura, quien realizó una de las obras más extraordinarias de investigación para el conocimiento de nuestra Patria. [...] Costa Rica, particularmente, continúa en deuda con él y este libro -modesto tal vez- pretende convertirse en un medio de acercamiento entre la ciudadanía nacional y su obra, para, de este modo, realizar un acto que podríamos llamar de verdadera justicia".?
}

La lectura del texto deja con claridad avizorar la magnitud de la obra de Henri Pittier. Solo la bibliografía citada acerca de su trabajo en Costa Rica es impresionante con 33 títulos. Pero el hecho que debe ser resaltado es, por una parte, la enorme riqueza de los materiales conocidos y el hecho que aún pueden aportar mucho en la profundización del conocimiento de la realidad costarricense. Así como, por otro lado, la probable existencia de más materiales sobre los habitantes del territorio costarricense y su historia, aún por ser conocidos y aprovechados por los científicos sociales interesados en la realidad sociohistórica

7 Conejo Guevara, Henri Pittier:..., 10. 
del país. Se tiene que además de los materiales del investigador suizo a los que se puede tener acceso en el país, sobre todo las colecciones que resguarda el Museo Nacional, ciertamente se conoce de la existencia de otros materiales relacionados con el trabajo de Henri Pittier con Costa Rica, que se encuentran en instituciones de distintos países, principalmente Venezuela y los Estados Unidos, y sobre los cuales se hace necesaria una sistematización de contenido, su ubicación y posibilidades de acceso. Pero también se abre la sospecha del desconocimiento de otros materiales que podrían ser sumamente valiosos para el conocimiento científico de la realidad costarricense. Una sospecha que abriría una línea de investigación sobre la producción misma de Henri Pittier.

Con esta perspectiva, en la necesidad de conocer y recuperar todo lo que se pueda de la obra de Henri Pittier, hay que detenerse críticamente en señalamientos tan esclarecedores como preocupantes citados o indicados por Adina Conejo. Se tiene, y como ejemplo de la posible existencia en otros países de materiales sobre la realidad costarricense, la cita del siguiente señalamiento crítico:

\begin{abstract}
"Secundan a Valerio, ${ }^{8}$ en esta labor, el Ingeniero don Horacio Ruiz Soto, quien visitó a Pittier, en su lecho de enfermo, unos meses antes de morir éste, y escribió unas pocas palabras en noviembre de 1949, en el Diario de Costa Rica. Transcribe allí dos cartas del sabio a nuestro Gobierno, en donde hace el ofrecimiento de obsequiar su colección de Etnografía y de Lingüística, las cuales no recibieron contestación". ${ }^{9}$
\end{abstract}

¿Cuál es el contenido de la mencionada colección en los campos de la etnografía y la lingüística ofrecida al Gobierno costarricense? ¿Qué nuevos e importantes trabajos de Pittier acerca de Costa Rica podrían estar contenidos en esas colecciones? Adina Conejo muestra un hombre de gran capacidad y voluntad de trabajo fuera de serie, que se traduce en una impresionante obra publicada producto de su labor en el país y que la autora recupera en su presentación de este investigador ${ }^{10}$. Por esto mismo, se abre una enorme expectativa sobre la posibilidad de la existencia de más materiales sobre Costa Rica, pero hasta ahora no conocidos en el país.

Pero también se indica en este libro de 1975, la existencia de materiales en Costa Rica que no han sido objeto de publicación y estudio:

8 Se refiere a Juvenal Valerio Rodríguez (1900-1971), científico costarricense quien llegó a ser director del Museo Nacional en los años treinta del siglo pasado y una de las personas que más han contribuido al (re) conocimiento de la obra de Henri Pittier en Costa Rica.

9 Conejo Guevara, Henri Pittier:..., 15.

10 La autora cita, pues, 33 obras de Pittier publicadas en Costa Rica sobre su labor en el país. Queda, entonces, la necesidad de inventariar otras obras publicadas en otros países y de materiales no publicados. 
"Como hemos señalado varias veces, el carácter observador de Pittier lo llevó a efectuar muchas giras a través del país. Así pudo visitar los Pueblos indígenas, recogió y escribió vocabularios. Esto lo sabemos por las narraciones en sus trabajos con don Carlos Gagini. Con él escribió uno en "Ensayo lexicográfico sobre lengua Térraba" en 1893. Actualmente existen todavía manuscritos, que se encuentran en la Biblioteca del Museo Nacional, en espera a ser publicados". ${ }^{11}$

Invita, pues, este texto de Adina Conejo a la tarea de recuperar en todo lo posible la obra científica producida por Pittier acerca de Costa Rica y sus gentes. Pertinencia de una invitación que se fundamenta precisamente por la actualidad de la empresa de investigación emprendida por Henri Pittier. Y para ello, como se indicó arriba, de seguido se comentan tres de los once textos del científico que la autora presenta como anexos ilustrativos de la obra del científico suizo en el territorio nacional.

\section{Una “Zona Azul”, vista como tal cien años antes}

La denominación de "Zona Azul" surge en los primeros años del siglo XXI entre la comunidad científica, ${ }^{12}$ y es ciertamente popularizada con la publicación, en 2009, del libro de Dan Buettner cuyo título al español se puede traducir como Las Zonas Azules: Lecciones para vivir más tiempo de las personas que han vivido más tiempo. ${ }^{13}$ Unos pocos lugares alrededor del planeta han llamado la atención producto de la constatación de que las personas que los habitan son mucho más longevas de la expectativa normal de vida. Por supuesto, esta comprobación de una situación circunscrita geográficamente de una longevidad que llega a superar los cien años ha despertado una enorme curiosidad entre demógrafos y científicos en general. De ahí el interés e importancia de la región guanacasteca de Nicoya, en Costa Rica, ya que esta es una de esas pocas zonas azules hoy conocidas como tales. ${ }^{14}$

Este hecho llevó, por ejemplo, a que en noviembre de 2017, se diera precisamente en la ciudad de Nicoya, un "Encuentro Mundial de Zonas Azules".

11 Conejo Guevara, Henri Pittier:..., 64.

12 Pareciera que hay consenso en la comunidad científica internacional acerca de que la denominación "Zona Azul" sobre este fenómeno de regiones donde sus habitantes presentan una prolongada longevidad, proviene de un artículo publicado en 2004, sobre un estudio en una región de la isla italiana de Cerdeña: Michel Poulain, Giovanni Mario Pes, Claude Grasland, Ciriaco Carru, Luigi Ferrucci, Giovannella Baggio, Claudio Franceschi, Luca Deiana, "Identification of a Geographic Area Characterized by Extreme Longevity in the Sardinia Island: the AKEA Study", Experimental Gerontology (EE. UU.) 39, n. 9 (septiembre, 2004): 1423-1429, DOI: https://doi.org/10.1016/j.exger.2004.06.016.

13 Dan Buettner, The Blue Zones: Lessons for Living Longer from the People Who've Lived the Longest (Washington, D. C., EE. UU.: National Geographic Society, 2017), 287.

14 Lo más común en la bibliografía especializada es destacar o considerar hoy como tales a cinco zonas azules: la isla japonesa de Okinawa; la región de Nuoro y Ogliastra en la isla italiana de Cerdeña; la isla griega de Icaria; la región de Loma Linda en California, Estados Unidos; y la Península de Nicoya en Costa Rica. 
Esfuerzo institucional costarricense que posibilitó, entre otras cosas, que se dieran cita en Guanacaste, algunos de los principales investigadores que alrededor del planeta se ocupan sobre este tema. Al respecto el mismo Dan Buettner resaltaba sobre el encuentro en Nicoya en el que participó:

\begin{abstract}
"Es un orgullo enorme ver los resultados de cómo la idea de investigar sobre el tema de la longevidad que surgió hace quince años se ve materializada en la reunión de los grandes científicos investigadores sobre el tema de las "Zonas Azules". Agrego que debemos de alguna forma emular, duplicar o copiar el estilo de vida de los centenarios y su manera de vivir, pero ante todo su medio ambiente, su dieta, la actividad, pero ante todo las conexiones que establecían, humanas no tecnológicas." $" 15$
\end{abstract}

No obstante, ya un siglo antes, en 1904, Pittier no solo había llamado la atención sobre la extraordinaria longevidad de muchos nicoyanos, sino que, además y muy sorprendentemente, trazó los lineamientos de lo que debería ser un programa de investigación científica, de total contemporaneidad, para dar cuenta de las causas de esta particular realidad demográfica en la región de Nicoya, Guanacaste. Lineamientos de investigación que no difieren, respecto de lo que hoy están haciendo los científicos ocupados por este fenómeno de una longevidad circunscrita regionalmente. En otras palabras, cien años antes de que la comunidad científica internacional le diera la denominación de "zona azul", Pittier ya había establecido la excepcional realidad demográfica de la región de Nicoya, y había trazado el camino para una investigación científica en búsqueda de una explicación científica del fenómeno. Un ejemplo de la actualidad del trabajo de Pittier que justamente quedó plasmada en su texto de "Impresiones y recuerdos: José Silverio Gómez (1801-1904)". ${ }^{16}$

En este texto recuperado por Adina Conejo, además de mostrar la acuciosidad e intuición científica para saber que se está frente de un hecho excepcional, en este caso demográfico, este muestra por parte de Pittier un excelente ejercicio de indagación por medio de fuentes orales, observación crítica y trabajo de campo, de lo que ha sido la vida de los habitantes de la Península de Nicoya. Es un trabajo que Pittier publica en 1904 y en el que recoge la entrevista a un nicoyano, de nombre José Silverio Gómez, quien ya para entonces había superado los cien años, donde queda bien establecido que esta condición longeva, no es en modo alguna excepcional en aquella región. Dice Pittier:

15 Palabras que son recogidas en el artículo: La Nación, boletín Revista Dominical, "Secretos azules para una longevidad saludable: 45 habitantes de la Península de Nicoya superaron los 100 años en noviembre. ¿Cuáles son sus secretos para vivir por tantos años?”, 26 de noviembre de 2017, URL: https://www.nacion.com/revista-dominical/secretos-azules-para-una-longevidad-saludable/ C6N2EUWN35FZRI5QQMLSK4RK34/story/.

16 Pittier, “Impresiones y recuerdos: José Silverio Gómez (1801-1904)”, en: Conejo Guevara, Henri Pittier:... 
"El hombre que encabeza estas líneas es el humilde nicoyano, nativo de Santa Ana y con quien tuve la oportunidad de celebrar una corta entrevista en los primeros días del corriente año. Me ha parecido interesante dedicarle un corto artículo, pues son escasos los hombres que como él han sido testigos presenciales de los acontecimientos de todo un siglo y que pueden exponer sus juicios retrospectivos y establecer comparaciones que no siempre resultan en ventaja del presente, a pesar de nuestros tan decantados progresos". ${ }^{17}$

Pero, más aún y, por otra parte, estamos aquí ante el investigador que se vale de la fuente oral para adentrarse en una realidad que el tiempo ha dejado atrás sobre las formas de vida en la Península de Nicoya. Más cuando el informante puede narrar como han sido, como él ha vivido las cosas en los últimos cien años: "Silverio Gómez no nació viajero. No conoce el interior de Costa Rica y escaso es el número de sus viajes al "Puerto", esto es, a Puntarenas". 18

Así, entonces, para Pittier, al tiempo que la avanzada edad del testigo constituye una excepcional oportunidad de acceder a información acerca del pasado de lo que ha sido la vida en la región nicoyana, tal longevidad del informante resulta también un hecho trascendente, mas no por ser algo excepcional sino, por el contrario, frecuente y propio de aquella región. Continúa resaltando el científico suizo:

\footnotetext{
"Ante todo, debo manifestar que, aunque no tengo motivos particulares para aspirar a dar a las generaciones venideras mi testimonio oral acerca de los sucesos que habré presenciado en mi terrenal peregrinación, me he quedado con deseos de ir a fijar mi residencia en Santa Ana, caserío cuyos moradores tienen el seguro privilegio de longevidad. En 1900, murió en dicho caserío - pues allí también se muere- y en pleno goce de sus facultades, el señor Patricio Juárez, ¡cuyos años alcanzaron a 117! En 1901, volvió al seno de nuestra madre común María Guevara, quien ignoraba su edad, pero que nuestro informante, Silverio Gómez, recuerda haber conocido mujer ya cuando él tenía 6 a 8 años. En fin, el señor Juan Reyes Gómez tiene hoy 98 años, con buenas probabilidades de completar el siglo". ${ }^{19}$
}

De esta forma y para principios del siglo XX, se tiene que Pittier constata la existencia de una región, que hoy es denominada "Zona Azul", espacio donde hay una prolongada expectativa de vida entre sus habitantes, a la vez que brinda una serie de datos genealógicos que son de evidente interés actual y vislumbra una excepcionalidad de la región nicoyana, que un siglo después será incorporada al reducido como selecto grupo de regiones que cumplen los requisitos de tal denominación.

17 Ibid, 136-137.

$18 \mathrm{Ibid}, 141$.

19 Ibid, 125-126. 
Pero no solo hace la constatación del dato de longevidad característico de lo que la comunidad científica hoy denomina como una "Zona Azul", sino que, y de una manera visionaria que es necesario reiterar, traza entonces los lineamientos de lo que debería ser un programa de investigación para dar cuenta de esa realidad demográfica y sus causas, con el mismo contenido y sentido de trabajo científico que más de cien años después orienta a los actuales investigadores que se ocupan del tema alrededor del mundo:

\footnotetext{
“A qué circunstancias especiales debe el Barrio de Santa Ana, situado en las colinas calcáreas al norte de la Villa de Nicoya, el privilegio de larga vida que ostentan sus moradores? Nadie lo ha dicho aún. ¿Será a la composición especial de sus aguas, a la suavidad de sus aires, a la vida sobria y arreglada de aquéllos, o tal vez simplemente al espíritu de imitación cuando no a la milagrosa intervención de la santa patrona del barrio? No lo sé, pero lo cierto es que en todas mis peregrinaciones por estas tierras no he encontrado otro rincón cuyos habitantes estén bendecidos con tal abundancia de años". ${ }^{20}$
}

Así, luego, aquella entrevista a José Silverio Gómez se torna no solo en un precedente en el conocimiento de una de las pocas zonas azules hoy reconocidas como tales en el planeta, sino, también deviene en ilustración del trabajo visionario de un científico que reconoce la importancia de un fenómeno demográfico que debe ser investigado.

De esta curiosa lectura, resulta claro que Henri Pittier no permaneció ajeno a los contornos socioculturales de la realidad con la que entró en contacto, y mucho menos desaprovechó en este caso la posibilidad de adentrarse en la historia de la forma de vida de la comunidad nicoyana y de su historia secular, a partir de la reconstrucción longitudinal de un destino individual, es decir, del testimonio de una persona cuya vida se torna testigo y testimonio de todo el siglo XIX.

\section{Indagando sobre el devenir del óköm}

Uno de los grandes aportes de Pittier en Costa Rica, ${ }^{21}$ está referido al conocimiento de algunos pueblos originarios que, como identidades étnicas diferenciadas a la denominada "sociedad nacional", sobrevivían en el actual territorio costarricense a la llegada del científico suizo a finales del siglo XIX. Muchos y de enorme importancia son los trabajos etnográficos y lingüísticos conocidos que dejó Pittier sobre sus encuentros con estos pueblos, siendo uno de ellos

20 Ibid, 126.

21 Pero este interés fue una constante del científico suizo en todos los países del continente americano en donde trabajó. 
"Ceremonias fúnebres", ${ }^{22}$ un documento en el que el investigador helvético describe las autoridades y rituales con que los bribris se hacían cargo de la muerte de uno de sus miembros. Un trabajo etnográfico de gran valor porque, entre otras cosas, permite estudiar los cambios de ciertas pautas culturales y sus causas que en el último siglo ha vivido este pueblo, cambios que tienen que ver, en general, con el proceso de negación de la diferencia étnica y la asimilación cultural forzada que enfrentan los denominados pueblos indígenas con respecto al Estado nacional. Negación y asimilación de la alteridad, negación y asimilación de los vencidos con la conquista y sometidos por la colonización que caracterizan la continuidad hasta el presente de lo que se conoce como "el hecho colonial".

Un ejemplo de estos cambios está claramente representado por el hecho de que hoy, los bribris, como también los cabécares, se ven obligados legalmente -por parte del Estado nacional- a enterrar el cuerpo de la persona fallecida. Sepultar el cuerpo es un proceder muy distinto a la forma cultural tradicional con que se protegía, envolviendo al fallecido, para ayudarlo y cuidarlo en el camino que emprendía una vez llegada la muerte. No hace mucho tiempo, por tanto, el cuerpo del difunto no era sepultado, sino más bien envuelto cuidadosamente, siguiendo un ritual ancestral, para ser colocado en el cementerio, un lugar especial en el bosque, en una especie de tarima o cama. Con el paso del tiempo se recogían los huesos para continuar con otros elementos rituales, alargando hasta en un año el funeral del fallecido. Un prolongado rito funerario cuya principal autoridad entre los bribris para hacerse cargo del cuidado del cuerpo y ayuda a la persona fallecida era el Óköm.

¿Pero, cómo definir al óköm? Dos de los principales investigadores contemporáneos de los denominados pueblos indígenas en Costa Rica, Carla Victoria Jara Murillo y Alí García Segura, ${ }^{23}$ ofrecen la siguiente definición:

\section{“Óköm: enterrador, encargado de los ritos fúnebres}

El encargado de los rituales fúnebres tiene un rango en la jerarquía de dignidades bribris que se ubica entre el cantor fúnebre -tsốkol- y la encargada de cuidar las piedras curativas del médico. Es el especialista en la manipulación de los cadáveres.

22 Pittier, "Impresiones y recuerdos: José Silverio Gómez (1801-1904)", en: Conejo Guevara, Henri Pittier:..., 114-119.

23 Carla Victoria Jara Murillo y Alí García Segura, Cargos tradicionales del pueblo bribri: Sĩõ tãmĩ - Óköm - Awá (San José, Costa Rica: Instituto de Investigaciones Lingüísticas, UCR; Instituto Costarricense de Electricidad, 2008), 195. 
Sánchez y Mayorga ${ }^{24}$ cuentan que cuando Itsã', uno de los diablos principales, se comía el cuerpo de sus víctimas y se iba a su cueva, los enterradores, con los parientes del muerto, aprovechaban para llevarse los restos". ${ }^{25}$

Pero debe observarse que, en esta definición, se asume sin más, la práctica de enterrar el cuerpo de la persona fallecida y de ahí, consecuentemente, que al óköm se le refiera en español como "enterrador", como "sepulturero". Pero este tipo de denominación oculta el cambio cultural, sus causas y consecuencias, que se ha producido en los últimos cien años, dado que enterrar el cuerpo es, pues, una práctica impuesta a los bribris en el proceso de negación-asimilación que sufren frente y desde la sociedad nacional costarricense.

Lo ancestral es que entre los bribris la persona fallecida no sea enterrada, siendo el óköm el encargado de cuidar y ayudar a esta persona en el nuevo transitar que emprende con la muerte. Así, el óköm es quien "envolvía", cuidando el cuerpo para prepararlo para el nuevo viaje, sacándolo de la casa que habitó y llevándolo a un lugar especial en el bosque para proseguir en ese tránsito. Es por esto por lo que la expresión bribri equivalente a "enterrar el cuerpo" usada en español por la sociedad nacional costarricense es para ellos "vaciar la casa". Se trata de dos sensibilidades, de dos concepciones culturales diferentes.

Henri Pittier, en su crónica, nos describe el tradicional rito fúnebre entre los bribris:

\begin{abstract}
"Al morir una persona, se llama inmediatamente a los ókub ${ }^{26}$ que empiezan por envolver el cadáver en una hamaca y, luego en una o varias piezas de mastate, y finalmente en las grandes hojas plateadas del murú-sik-Calathea sp.-. El bulto es cuidadosamente amarrado por medio de bejucos, y después se transporta a un lugar apartado en donde se coloca en medio del monte, encima de un andamio construido para este objeto; se cubre todavía con más hojas de murú-sik y por encima se amarra otra hamaca para impedir que algún animal se lleve los huesos. Mientras tanto que los ókub cumplen con su fúnebre tarea, un stsúkur ${ }^{27}$ canta sin cesar sentado delante del fogón y encomendando al alma del difunto a los buenos espíritus". ${ }^{28}$
\end{abstract}

Repárese en todo el cuidado de "envolver el cadáver", para llevarlo "a un lugar apartado en donde se coloca en medio del monte, encima de un andamio construido para este objeto". No solo se trata de un valioso material etnográfico legado por Pittier, sino que es una sugestiva referencia que impone la interrogante

24 Juanita Sánchez y Gloria Mayorga, Se' Síw $\underline{a}^{\prime}$. Nuestras tradiciones. Costumbres y tradiciones bribris (San José, Costa Rica: Comisión Costarricense de Cooperación con la UNESCO, 62).

25 Jara Murillo y García Segura, Cargos tradicionales ..., 6.

26 Dados los avances en el conocimiento y reconocimiento de la lengua bribri, hoy la escritura del nombre de esta autoridad tradicional es el óköm.

27 Tsö́kol, es un cantor fúnebre.

28 Henri Pittier, "Supersticiones y ceremonias fúnebres de los indios bribri", en: Conejo Guevara, Henri Pittier:..., 114. 
de cómo fue cambiando esta costumbre en los últimos cien años. En este mismo sentido, Carla Jara y Alí García en su trabajo ya citado recuperan el testimonio de un óköm contemporáneo, quien en la entrevista refiere a sus antecesores: “... los mayores envolvían antiguamente en hojas de bijagua, no era una caja". ${ }^{29}$

No se trata, pues, solo de describir un estado de cosas en un momento dado. El aporte científico debe dar cuenta del cambio social, de sus causas y de sus consecuencias. Más cuando se está al frente de un hecho colonial que dice de vencedores y vencidos, de colonizadores y de colonizados. Pero, al mismo tiempo, dice de resistencia cultural y de la lucha sociopolítica de los pueblos sometidos por seguir existiendo como tales, como identidades culturales diferenciadas. Una tarea donde la información sobre el pasado se vuelve imprescindible. Ciertamente en su libro, Carla Jara y Alí García, describen tal cambio:

\begin{abstract}
"Antiguamente, nosotros los bribris no nos enterrábamos, sino que nos envolvíamos, se envolvía a la gente; entonces por ejemplo ese tipo de juegos, como envolverse en algo, no se puede hacer. También, el niño que va a ser óköm aprende que si va a alzar a un niño, no lo puede hacer horizontalmente, solo verticalmente. Siempre tiene que estar atento a cumplir esas conductas; son métodos de educación para cuando él ya va a ejercer su cargo sea lo más riguroso y correcto en sus actividades". ${ }^{30}$
\end{abstract}

Pero la pregunta que se plantea es sobre el porqué, sus causas y direccionalidad, del cambio cultural. De ahí la importancia y actualidad del trabajo de Pittier. De hecho, Murillo y García citan otras tres obras de Pittier, más referidas a cuestiones lingüísticas. Pero el cambio cultural adquiere una dimensión política -la lucha de un pueblo como el bribri por reivindicar su derecho a seguir existiendo como tal-, donde la explicación de un cambio cultural tan importante como los ritos funerarios, por ejemplo, cobra gran importancia sociopolítica como también jurídica. Estos autores, ciertamente, brindan mucha información sobre la importancia del óköm entre los bribris:

"El estudiante debe aprender cuáles plantas son buenas para ayudar el alma del difunto en su viaje al más allá, con el fin de que no sufra o haga sufrir a la gente en este mundo, sus familiares, por ejemplo. El estudiante de óköm debe saber cuál planta, cuál bejuco es bueno para cada paso. Cuando ve una imagen rápida, cómo interpretar esto, cómo actuar. Si escucha una cosa que no está identificada, qué hay que decir y cómo hay que caminar: debe saber cómo retroceder, si seguir o no seguir. Estos son datos importantes porque él va a enterrar a una persona o dejarla en el monte, puede haber informaciones naturales que debe saber interpretar. También debe aprender a cortar las hojas para envolver el muerto, saber cómo se agarra la

29 Jara Murillo y García Segura, Cargos tradicionales..., 77.

30 Ibid, 63. 
hoja, cuál es la hoja que se usa, que es mũlù̀sik 'bijagua'; es una hoja grande que crece en los pantanos, de un lado es blanca y del otro verde". ${ }^{31}$

Pero la dimensión del cambio cultural, de sus orientaciones y causas, así como de sus consecuencias, es algo que debe ser solventemente estudiado, por la importancia que tiene para la misma sobrevivencia de un pueblo. Desde esta perspectiva, la recuperación de procesos del pasado, que abre seminalmente Pittier, cobra total actualidad.

\section{Descubriendo la "Zona Sur"}

La llamada "Zona Sur" fue uno de los últimos territorios en ser incorporados al proyecto del Estado nacional costarricense y que figuraba únicamente groso modo en los mapas de la segunda mitad del siglo XIX, sin tener aún ni siquiera bien deslindadas las fronteras con la República de Colombia. Para cuando Pittier llegó al país en 1887, la sociedad costarricense se veía contenida hacia el sur por fronteras naturales como las grandes elevaciones de la cordillera de Talamanca y el Cerro de la Muerte con sus gélidos climas, y más allá apenas se iniciaba la colonización, por ejemplo, del Valle del General. Y es en ese contexto de falta de domesticación y particular desconocimiento del territorio que Pittier se convierte en uno de los más importantes exploradores-descubridores de la historiografía nacional:

\footnotetext{
"Subió a casi todos los picos más altos de nuestro territorio y a nuestros volcanes y bajó hacia las costas. Quizá lo más importante de sus esfuerzos, fueron sus giras a la zona sur del país, región casi inexplorada por entonces. Allí fue el descubridor, y ratificó muchos nombres de valles, cerros, ríos y quebradas. Fue él, quien realmente bautizó muchas de esas localidades ... Nuestro personaje en estudio dejó una gran cantidad de escritos que han sido básicos para nuestros geógrafos. Hizo observaciones de ríos para aprovechar su vía fluvial. Así nos lo demuestra en su informe de la parte meridional del país... Lo vemos determinar caminos, que, a la postre, fueron construidos por donde él indicó. También dio itinerarios, como se puede comprobar en el Viaje de exploración al valle del rio Grande de Térraba (1892)". ${ }^{32}$
}

Y sumamente ilustrativo de la enorme importancia de ese "descubrir" la Zona Sur, como actualidad de la información que suministra, que incluye significativas referencias sobre pueblos indígenas, es la crónica de viaje "Ojeada general sobre el Valle del Diquís o Río de Térraba". Dice Pittier sobre ese territorio:

31 Ibid, 65 .

32 Conejo Guevara, Henri Pittier:..., 59-60. 
"Por toda la extensión de la región en referencia, la que calculo en $11.000 \mathrm{~km}^{2}$ encuéntranse vestigios de antiguas y numerosísimas poblaciones. En Buenos Aires, por ejemplo, se ven los restos bien conservados aún de un caserío considerable, con edificios grandes, y, en los alrededores, hay millares de entierros o huacas. Hoy día, sólo se encuentran cuatro reducidos núcleos, a saber: El General con 284 habitantes, Buenos Aires, con 279, Térraba, con 214 -incluyendo la gente esparcida por los valles de Cabagra- y Boruca, con 389 ... Entre estos pueblos, los dos últimos son los postreros restos de los antiguos poseedores del suelo: van disminuyendo poco a poco y, en un porvenir no muy lejano las piedras de moler quedarán como únicos testigos de caseríos en un tiempo florecientes. En Buenos Aires y El General viven exclusivamente blancos y mestizos, pero la población no arroja un aumento muy satisfactorio, debido a la poca migración, así como también a las mil dificultades frente a las cuales la gente sucumbe muy a menudo, por falta completa de los indispensables recursos.

Así es que el inmenso Valle del Diquís apenas cuenta por entonces con $12 \mathrm{~km}^{2}$ cuando podría sustentar cien veces más, y que la región llamada Meseta Central tiene una densidad de no menos de 138, equivalente casi al promedio que arroja Holanda y muy superior al promedio de Europa". ${ }^{33}$

Henri Pittier se torna, luego, en una fuente de gran importancia y pertinencia para todos aquellos investigadores que en el presente trabajan en dar cuenta del proceso histórico de conformación de la nación costarricense, especialmente en lo relativo al proceso de colonización y expansión hacia el sur del Valle Central. Trama que conlleva la particularidad que interesa resaltar en la presente reflexión, de ser en mucho definitoria de la relación que, con sus distintos momentos y contenidos, ${ }^{34}$ el Estado costarricense ha ido construyendo con los pueblos indígenas sobrevivientes en su territorio. En el sur del país, se tiene un proceso de colonización tardío que, aunque impulsado desde la segunda mitad del siglo XIX, comienza a consolidarse y tomar vigor hacia las primeras décadas del siglo XX, y donde el Estado se reencontrará con la realidad de la persistencia de pueblos indígenas tras casi un siglo de alcanzada la independencia y

33 Henri Pittier, "Ojeada general sobre el Valle del Diquís o Río de Térraba", en: Conejo Guevara, Henri Pittier:..., 81.

34 Una relación contradictoria en el tiempo, que va desde un desconocimiento legal y una política pública de asimilación cultural de los pueblos indígenas durante el período republicano -que se inicia con la independencia- hasta, por ejemplo, el reciente cambio que se hizo mediante la Ley № 9.305 del 24 de agosto de 2015 del primer artículo de la Constitución Política de la República de Costa Rica, el cual fue modificado cambiando que, "Costa Rica es una República democrática libre e independiente" a que "Costa Rica es una República democrática, libre, independiente, multiétnica y pluricultural”. Se tienen, entonces, momentos cualitativamente distintos de una relación que va desde el desconocimiento por parte del Estado de que la condición de "indígena" sea portadora de derechos legales específicos, hasta las actuales luchas que libran los pueblos indígenas por territorios y autonomía sobre la base del desarrollo del conjunto de normas internacionales vinculantes para el Estado costarricense que, en general, se conocen como "derechos humanos" -que incluyen el derecho a la autodeterminación de los pueblos-y que específicamente tienen expresiones en instrumentos como el Convenio 169 de la Organización Internacional del Trabajo (OIT), Convenio sobre Pueblos Indígenas y Tribales en Países Independientes, adoptado por Costa Rica por medio de la Ley № 7.316 del 27 de junio de 1989. 
haber declarado y decretado su extinción como identidad étnica diferenciada en función de su asimilación forzada a la "nación costarricense", a la "ciudadanía costarricense". Así, y Costa Rica no es ninguna excepción en el continente, en el proyecto liberal republicano de nación que surge con el derrumbe del imperio colonial no había cabida para "el indio" como una identidad sociopolítica diferenciada, como no había tampoco espacio para la persistencia de tierras ejidales o comunales frente a la lógica capitalista de privatización y mercantilización de la tierra: "el indio" era un producto colonial que debía desaparecer al ser asimilado por la nueva identidad social y ciudadana: "el costarricense". De ahí, la contradicción que se presenta cuando ya entrado el siglo XX, el Estado costarricense constata, principalmente al sur del país, no solo la sobrevivencia en su territorio de distintos pueblos indígenas sino que, además y resultado de una nueva sensibilidad sociopolítica que se conocería como "el indigenismo interamericano", ${ }^{35}$ se inicia en esos años y en todo el continente un reconocimiento de derechos étnicamente diferenciados, incluido lo relativo a la tenencia de la tierra, pasando de políticas de asimilación cultural que conllevaban la desaparición de las tierras comunales a volver a reconocer legalmente una posesión comunitaria de territorios ancestrales. Y Pittier se encontraría inmerso en este movimiento contradictorio: de un lado, él participaba activamente en la exploración geográfica como parte del impulso estatal a la empresa de colonizar y privatizar los territorios de la periferia del Valle Central. Pero al mismo tiempo, él es uno de los primeros en llamar la atención de la importante presencia de población indígena en aquellos territorios "baldíos". Sin duda, Henri Pittier fue uno de los más importantes investigadores que se interesó a finales del siglo XIX por los pueblos indígenas que habitaban el sur del país. Una presencia étnica que es resultado de un relativo aislamiento con respecto a la "sociedad nacional" y que responde a la categoría de "regiones de refugio" del antropólogo Beltrán Aguirre. ${ }^{36}$ Para el caso de Costa Rica, esta sobrevivencia en la "periferia" es el caso de, por ejemplo, los malekus en las llanuras del norte fronterizas con Nicaragua, en las tierras de la cordillera de Talamanca los cabécares y los bribris y en el sur camino a Panamá, los teribes, los bruncas o los ngäbes.

Se presenta aquí, entonces, una paradoja en el proceso de conformación de la nación costarricense que en el siglo XIX suponía la desaparición del indígena y la privatización de la tierra, pero que, en un movimiento inverso

35 Se trata de un movimiento sociopolítico a nivel continental que conllevará al establecimiento de políticas estatales de protección y reconocimiento de derechos específicos a los pueblos indígenas en tanto tales. Un punto culminante de este movimiento fue la realización del "Primer Congreso Indigenista Interamericano" que tuvo lugar en 1940 en Pátzcuaro, Michoacán, México. Encuentro que produce la "Convención de Pátzcuaro", que contiene una serie de principios que fueron adoptados por los países como políticas públicas, así como la creación misma del Instituto Indigenista Interamericano.

36 Gonzalo Beltrán Aguirre, Obra antropológica, IX. Regiones de refugio: El desarrollo de la comunidad y el proceso dominical en Mestizoamérica (México, D.F.: FCE; UV; INI; GEV, 1991), 376. 
para el siglo XX, y especialmente en lo relativo al proceso de colonización y expansión de los territorios hacia el sur del Valle Central, se da un reconocimiento estatal de la persistencia de pueblos indígenas y de su derecho legal de mantener su identidad y territorios. Esta paradoja se expresa y concreta con la promulgación en 1939 de la Ley General sobre Terrenos Baldios, que tenía el propósito de resolver en definitiva el proceso de colonización de todo el país y consolidar la privatización de la tierra por parte de la "sociedad nacional", pero, contradictoriamente, al mismo tiempo reconoce derechos comunitarios a poblaciones indígenas sobrevivientes:

\begin{abstract}
"Artículo $8^{\circ}$ - Se declaran también inalienables los terrenos comprendidos en las dos riberas del río Banano, diez kilómetros aguas arriba, en una extensión de quinientos metros de cada lado, protegiendo así las fuentes que surtan o puedan surtir en lo futuro la cañería de Limón. Asimismo se declara inalienable y de propiedad exclusiva de los indígenas, una zona prudencial a juicio del Poder Ejecutivo en los lugares en donde existan tribus de éstos, a fin de conservar nuestra raza autóctona y de librarlos de futuras injusticias". ${ }^{37}$
\end{abstract}

Así, de manera contradictoria, con esta ley que responde a la lógica capitalista de privatización y mercantilización de la tierra, los indígenas no solo, por un lado, "son redescubiertos legalmente" por el Estado -que había decretado, ya se ha mencionado, su extinción cien años antes con la consolidación del proyecto republicano liberal burgués-, al encontrar grandes territorios poblados por bribris, cabécares, telires, etc., sobre todo al sur del país, que sencillamente, entonces, no estaban baldíos, tal como lo hiciera ver Henri Pittier ya desde finales del siglo XIX y principios del siglo XX, sino que, por otra parte, convertiría a los pueblos indígenas, en contradicción a la lógica capitalista, en sujetos de derechos comunitarios tales como el derecho de ser poseedores colectivos de sus territorios. Un proceso sin duda lleno de todo tipo de fricciones de creación de "territorios indígenas" que se inicia, luego, en 1939, y que hoy se expresa en la existencia legal de 24 territorios en manos de ocho etnias indígenas. ${ }^{38} \mathrm{Un}$

37 Congreso Constitucional de la República de Costa Rica, Ley General sobre Terrenos Baldíos, 10 de enero de 1939. El resaltado es original.

38 La relación entre el Estado nacional costarricense y los pueblos indígenas sobrevivientes va a pasar, pues, por distintos momentos, desde la negación legal-asimilación cultural de los pueblos indígenas que se da con la independencia y el proyecto republicado de nación, al actual reconocimiento por parte del Estado del derecho de estos pueblos a existir como entidades étnicamente diferenciadas y poseedoras de sus propios territorios. Un momento de reconocimiento legal del derecho a la tierra que se inicia, paradójicamente, con la Ley General sobre Terrenos Baldios de 1939, cuya finalidad es consolidar el proceso de privatización de la tierra, pero en este mismo instrumento legal se crea el primer territorio indígena. Se inicia, entonces, un movimiento difícil y lleno de fricciones económicas, sociales y políticas de reivindicación legal de territorios indígenas que vendrá a tener un momento de consolidación jurídica con la Ley Indígena $\mathrm{N}^{\circ} 6.172$, promulgada el 29 de noviembre de 1977. Proceso que se ve acompañado por una serie de normas legales internacionales como, por ejemplo, el Convenio 169 de 1989, Convenio sobre Pueblos Indígenas y Tribales de la OIT, que suscribe Costa Rica en 1993. 
movimiento contradictorio que tiene que ver, por tanto, con la persistencia de poblaciones indígenas frente a la expansiva ocupación territorial de la sociedad nacional ligada a fuertes desarrollos de producción capitalista como lo que sucedió, por ejemplo, con el enclave bananero en el Atlántico del país primero y luego en el Pacífico. ${ }^{39}$ Una dinámica que ya encuentra Henri Pittier en el relato del nicoyano José Silverio Gómez:

\begin{abstract}
"Gómez afirma que en la primera mitad del Siglo XIX, la villa de Nicoya y varios de sus barrios eran mucho más poblados, A primera vista este dato parece estar en oposición con los hechos; sin embargo, no está por completo desprovisto de razón. Ha pasado en Nicoya lo que en los pueblos del Valle de Diquís: por una parte, una vez que los misioneros abandonaron los indios, éstos cedieron a sus naturales instintos y buscaron otra vez el monte; por otra, si bien constan de los documentos oficiales que la población ha seguido en aumento, no menos cierto que el número de los naturales ha disminuido". ${ }^{40}$
\end{abstract}

Henri Pittier entiende que una dinámica de expansión de la sociedad nacional sobre el territorio nacional, que conlleva la privatización de la posesión de la tierra, entraba en contradicción con la sobrevivencia de los pueblos indígenas. El mismo Pittier viene a Costa Rica a sentar las bases institucionales para el conocimiento geográfico científico que posibilite precisamente la privatización de la tierra en esa expansión de la sociedad nacional sobre nuevos territorios. Pero en su trabajo descubre las poblaciones indígenas que se asientan en los territorios hacia donde se dirige dicha expansión. Así, el trabajo de Henri Pittier descubriendo lo que se conoce hoy como la Zona Sur, está en la base de este proceso de cambios de la relación entre los pueblos indígenas y el Estado costarricense. Recuérdese que la Zona Sur, que se extiende desde el Valle del General hasta la frontera con Panamá, tiene en la construcción de la Carretera Interamericana -en una fecha tan tardía como los años cuarenta del siglo pasado y construida con la participación del Ejército de los Estados Unidos en el contexto de la Segunda Guerra Mundial- el medio de transporte clave para su colonización e integración a la nación costarricense. Es en medio de esta tardía expansión de la "sociedad nacional" hacia nuevos territorios, pero al mismo tiempo en el contexto de esta nueva sensibilidad, la del "indigenismo interamericano", donde, ciertamente, 1939 se convierte en una fecha clave para entender la sobrevivencia contemporánea de la mayoría de los pueblos indígenas que todavía hoy habitan el país: el 10 de enero de 1939 se firma por el Presidente de la República, León Cortés

39 Aquí debe indicarse también lo que fue la expansión del enclave bananero en tierras del Atlántico ocupadas para la época principalmente por población bribri, recordando la muerte del último "Rey de Talamanca", Antonio Saldaña, en 1910.

40 Pittier, "Impresiones y recuerdos: José Silverio Gómez (1801-1904)", en: Conejo Guevara, Henri Pittier:..., 139-140. 
Castro, la ya referida Ley General sobre Terrenos Baldios. Sin duda en la base de estos hechos legales, está todo el trabajo de "descubrir" la Zona Sur y Henri Pittier es el autor de uno de los grandes aportes en esta empresa nacional. Desde esta perspectiva, los trabajos de exploración del científico europeo se vuelven imprescindibles para entender el significado histórico de una "Zona Sur" que exploró para abrirla al conocimiento de la nación costarricense, así como para sentar las bases de nuevas políticas de colonización como fue el caso, entonces, de la promulgación de la Ley General sobre Terrenos Baldíos.

\section{A manera de conclusión}

Si bien el trabajo de investigación en Costa Rica de Henri Pittier continúa sin ser conocido en su totalidad, en campos como la geografía o la botánica han sido reconocidos y aprovechados en el país a lo largo de los años muchos de sus textos, pero sus aportes en áreas como la etnografía, la historia y la lingüística son menos conocidos. En este sentido, el texto de Adina Conejo de 1975 puede ser leído como una invitación a descubrir el extraordinario legado de Pittier y valorar su importancia en particular para las ciencias sociales.

En la presente reflexión, se ha asumido esta inquietud y mostrado por medio de comentar tres de los once trabajos que Adina Conejo rescata del investigador suizo, tratando de recuperar la actualidad que tiene el legado de Pittier en campos como la historia, la demografía y la etnografía. Una muestra que permite positivamente sospechar la enorme riqueza que podría estar contenida en trabajos del científico suizo que aún quedan por descubrir y valorar. Pero al mismo tiempo, señalar que debe volverse a estudiar con cuidado mucho de ese legado actualmente disponible en el país, siempre en función de los intereses de la investigación social que hoy se realiza. 
